\title{
Role of menin in the regulation of telomerase activity in normal and cancer cells
}

\author{
MANABU HASHIMOTO ${ }^{1}$, SATORU KYO ${ }^{1}$, XIANXIN HUA ${ }^{3}$, HIDETOSHI TAHARA ${ }^{4}$, MIKI NAKAJIMA ${ }^{2}$ \\ MASAHIRO TAKAKURA ${ }^{1}$, JUNKO SAKAGUCHI ${ }^{1}$, YOSHIKO MAIDA ${ }^{1}$, MITSUHIRO NAKAMURA ${ }^{1}$, \\ TOMOMI IKOMA $^{1}$, YASUNARI MIZUMOTO ${ }^{1}$ and MASAKI INOUE ${ }^{1}$ \\ Departments of ${ }^{1}$ Obstetrics and Gynecology and ${ }^{2}$ Drug Metabolism and Toxicology, \\ Kanazawa University Graduate School of Medical Science, Kanazawa, Ishikawa 920-8641, Japan; \\ ${ }^{3}$ Department of Cancer Biology, University of Pennsylvania, PA, USA; ${ }^{4}$ Department of Cellular and Molecular Biology, \\ Division of Integrated Medical Science, Graduate School of Biomedical Sciences, Hiroshima University, Japan
}

Received January 17, 2008; Accepted March 7, 2008

DOI: 10.3892/ijo_00000013

\begin{abstract}
Transcriptional activation of human telomerase reverse transcriptase ( $h T E R T)$ is critical for telomerase expression, a major step for cellular immortality and carcinogenesis. Although several transcriptional activators have been identified, factors responsible for repressing the $h T E R T$ promoter are largely unknown. Gene screening that employed enhanced retroviral mutagenesis has identified potential hTERT repressors. Among these, menin, which is a tumor suppressor and a gene product of MEN1, has been reported to play a critical role. In the present study, we further analyzed menin's role in the transcriptional regulation of $h T E R T$ in normal and cancer cells. Luciferase reporter assays that use the hTERT promoter have demonstrated that an overexpression of menin decreases the transcriptional activity of the $h T E R T$ gene in a cell-type specific manner. Mutation and deletion analyses of the $h T E R T$ promoter demonstrated that there was no specific site on the promoter that was responsible for the menin-mediated transcriptional inhibition. An electrophoretic mobility shift assay using recombinant menin protein generated the binding complexes with the $h T E R T$ promoter, which was completely diminished by the addition of poly-dI-dC. This indicates that there is a sequence-independent binding of menin. RT-PCR assays have revealed that overexpression of menin inhibits hTERT mRNA expression in some cell types, although this inhibition does not lead to a significant down-regulation of telomerase activity. In cancer cell lines and in normal cells, the siRNA-based inhibition of MENI does not lead to the up-regulation of hTERT mRNA expression. No significant
\end{abstract}

Correspondence to: Dr Satoru Kyo, Department of Obstetrics and Gynecology, Kanazawa University Graduate School of Medical Science, 13-1 Takaramachi, Kanazawa, Ishikawa 920-8641, Japan E-mail: satoruky@med.kanazawa-u.ac.jp

Key words: telomerase, hTERT, menin, transcription, regulation correlation has been found between menin and hTERT mRNA expressions in a variety of cancer cell lines and clinical tissue samples. Thus, while menin appears to have some inhibitory effects on the $h T E R T$ promoter, possibly via the sequence-independent binding to the promoter, the present study does not support the hypothesis that menin has a crucial role in the determination of telomerase activity in normal and cancer cells.

\section{Introduction}

The role of telomerase in human carcinogenesis has been extensively studied in the past decade, with over $90 \%$ of human cancers found to have a telomerase activation (1) that contributes to the stabilization of telomeres and confers cells an unlimited replicative capacity. Extensive efforts have been made to clarify the molecular mechanisms of telomerase activation, but little is known about the mechanisms of cancer-specific telomerase activation (2). Experimental evidence indicates that the catalytic subunit protein of telomerase, human telomerase reverse transcriptase (hTERT), is a critical determinant of telomerase activity within the cell $(3,4)$. Additionally, it has also been noted that the promoter activity of $h T E R T$ is tightly regulated in a cancer-specific manner (5). Although a number of transcription factors have been identified as being regulators of the hTERT promoter, most are not cancer-specific, and thus, the molecular mechanisms responsible for this promoter's cancer specific activation have yet to be elucidated. One possible explanation for this cancer specificity is the presence of transcriptional repressors of $h T E R T$ that are contained predominantly in normal cells.

Recently, Lin et al (6) identified several negative regulatory factors for $h T E R T$ by means of gene screening that used enhanced retroviral mutagenesis (ERM). They identified menin, SIP1, Mad1, hSIR2 and BRIT1 as candidates for the hTERT repressor. They also demonstrated that the tumor suppressor menin was the most representative repressor of $h T E R T$. Menin is primarily a nuclear protein that consists of 610 amino acid residues. The gene encoding menin, 
$M E N 1$, is frequently mutated in patients with inherited tumor syndrome, which is characterized by multiple endocrine tumors and referred to as multiple endocrine neoplasia type 1 (MEN1) $(7,8)$. There is no obvious motif for menin that would suggest it has a tumor suppressing function and additionally, it is poorly understood how menin is able to suppress tumorigenesis. Recent studies have identified various menin-interacting proteins, such as JunD $(9,10)$, NF- $\mathrm{BB}$ (11), and mSin3A-histone deacetylase $(12,13)$. While these various proteins suggest that menin acts as a regulator of gene transcription, little is known about the role that menin plays in the regulation of the hTERT promoter.

We wished to investigate several aspects regarding whether menin regulates $h T E R T$ transcription and telomerase activity, and if so, how this is accomplished. Does the constitutive expression of menin affect hTERT expression in normal and cancer cells? Is menin involved in the silencing of hTERT in normal cells? Based on current knowledge in the field in conjunction with our above questions, we analyzed the roles of menin with regard to the regulation of hTERT and telomerase in both human cancer and in normal cells.

\section{Materials and methods}

Cell lines and tissue samples. All the cell lines used in the present study, including human cervical cancer C33A and HeLa cells, breast cancer MCF-7 cells, normal human fibroblast BJ cells and NHF cells, were incubated in Dulbecco's modified Eagle's medium (DMEM) with $10 \%$ fetal bovine serum (FBS) in the presence of $5 \% \mathrm{CO}_{2}$ at $37^{\circ} \mathrm{C}$. Human tissue samples of liver cancer and normal liver were collected by biopsy or surgery at Hiroshima University Hospital after written informed consent was obtained from each patient. After pathological confirmation, the samples were stored at $-80^{\circ} \mathrm{C}$ until use.

Luciferase reporter assay. Luciferase reporter plasmids containing various lengths of hTERT promoter or mutant hTERT promoter were prepared as previously described $(5,14,15)$. Briefly, $0.2 \mu \mathrm{g}$ of menin expression vectors (pCMVsportMenin) (9), which were kindly provided by Dr Sunita K. Agarwal (National Institutes of Health, Bethesda, MD, USA), or blank vector were transfected into various cell lines together with $0.4 \mu \mathrm{g}$ of luciferase reporter plasmids into 24-well dishes using Lipofectamine PLUS ${ }^{\mathrm{TM}}$ (Invitrogen Corp., Carlsbad, CA, USA) according to the manufacturer's protocol. Forty-eight hours after the transfection, cell lysates were extracted and luciferase assays were performed using the Dual-Luciferase Reporter Assay System (Promega, Madison, WI, USA), in which Renilla luciferase plasmids were co-transfected as a control to normalize the transcription efficiency. All experiments were performed at least 3 times for each plasmid, with the average of 3 resultant values used as the reported relative luciferase activity.

Electrophoretic mobility shift assay. The recombinant carboxy-terminus of the menin protein was prepared as has been previously described (16). Approximately, $0.3 \mu \mathrm{g}$ of protein was incubated with poly $\mathrm{dI}-\mathrm{dC}$ in a $25 \mu 1$ reaction volume containing $10 \%$ glycerol, $25 \mathrm{mM}$ HEPES ( $\mathrm{pH} 7.9$ ), $50 \mathrm{mM} \mathrm{KCl}, 0.5 \mathrm{mM}$ PMSF and $1 \mathrm{mM}$ dithiothreitol for $15 \mathrm{~min}$ at room temperature. Following the incubation, $10,000 \mathrm{cpm}$ of $\left[{ }^{32} \mathrm{P}\right]$-end-labeled probe containing $181 \mathrm{bp}$ of the hTERT core promoter was added and the reaction was further incubated at $4^{\circ} \mathrm{C}$ for $20 \mathrm{~min}$. Following electrophoresis on a $4 \%$ polyacrylamide gel, the gel was dried and subjected to autoradiography using a Fuji BAS-III Bioimaging Analyzer (Fuji Photo Film, Kanagawa, Japan).

TRAP assay. Telomerase activity was measured by a TRAP assay that used the TRAP-eze Telomerase Detection Kit system in accordance with the manufacturer's protocol (Intergen, Purchase, NY, USA).

RT-PCR assay. Total RNA was extracted from surgical tissue specimens using NucleoSpin RNA II (MacheryNagel, Düren, Germany), followed by reverse transcription using SuperScript II Reverse Transcriptase and oligo (dT) primers (SuperScript First-Strand Synthesis System for RTPCR; Invitrogen). The mRNA expressions of the hTERT or MEN1 gene were measured using the fluorescence-based TaqMan real-time RT-PCR, with detection performed using the ABI PRISM 7000 Sequence Detection System (Applied Biosystems, Foster City, CA, USA). Real-time RT-PCR was performed with a $40 \mu 1$ reaction mixture that contained $2 \mathrm{X}$ TaqMan Universal PCR Master Mix (Applied Biosystems), $900 \mathrm{nM}$ forward and reverse primers and $200 \mathrm{nM}$ probe. After $2 \mathrm{~min}$ at $50^{\circ} \mathrm{C}$ and $10 \mathrm{~min}$ at $95^{\circ} \mathrm{C}$, amplification was performed for 40 cycles at $95^{\circ} \mathrm{C}$ for $15 \mathrm{sec}$ and then at $60^{\circ} \mathrm{C}$ for $60 \mathrm{sec}$. GAPDH mRNA expression served as the control, with detection performed using Assays-on-Demand Gene Expression products (20x primer and probe mix) for GAPDH (Applied Biosystems).

The expression of hTERT or menin mRNA was also analyzed by semi-quantitative RT-PCR. Briefly, total RNA was isolated from cells using Isogen (Nippon Gene, Tokyo, Japan) in accordance with the manufacturer's protocol. A RNA PCR kit version 2 (Takara, Otsu, Japan) with random primers was used for cDNA synthesis from $1 \mu \mathrm{g}$ of RNA. Subsequently, $2 \mu 1$ aliquots of the reverse-transcribed cDNA were subjected to PCR in $50 \mu 1$ of $1 \mathrm{X}$ buffer [10 mM Tris$\mathrm{HCl}$ (pH 8.3), $\left.2.5 \mathrm{mM} \mathrm{MgCl}_{2}, 50 \mathrm{mM} \mathrm{KCl}\right]$ containing $1 \mathrm{mM}$ each of dATP, dCTP, dGTP and dTTP, 2.5 units of Taq DNA polymerase (Takara) and $0.2 \mu \mathrm{M}$ each of the specific primers for hTERT mRNA, 5'-CGGAAGAGTGTCTGG AGCAA-3' (LT5) and 5'-GGATGAAGCGGAGTCTGGA-3' (LT6) (3). Each aliquot underwent 28 cycles of denaturation at $94^{\circ} \mathrm{C}$ for $30 \mathrm{sec}$, with annealing at $60^{\circ} \mathrm{C}$ for $30 \mathrm{sec}$ and extension at $72^{\circ} \mathrm{C}$ for $90 \mathrm{sec}$. PCR products were electrophoresed in $7 \%$ polyacrylamide gel and stained with SYBRGold (Molecular Probes, Eugene, OR, USA). The efficiency of cDNA synthesis from each sample was estimated by PCR that used $\beta$-actin-specific primers, as has been described previously (3).

RNA interference assay. For menin RNA interference, various cell lines were exposed to Lipofectamine reagent (Invitrogen) in the presence of $100 \mathrm{nM}$ siRNA against menin (Ambion, 
A

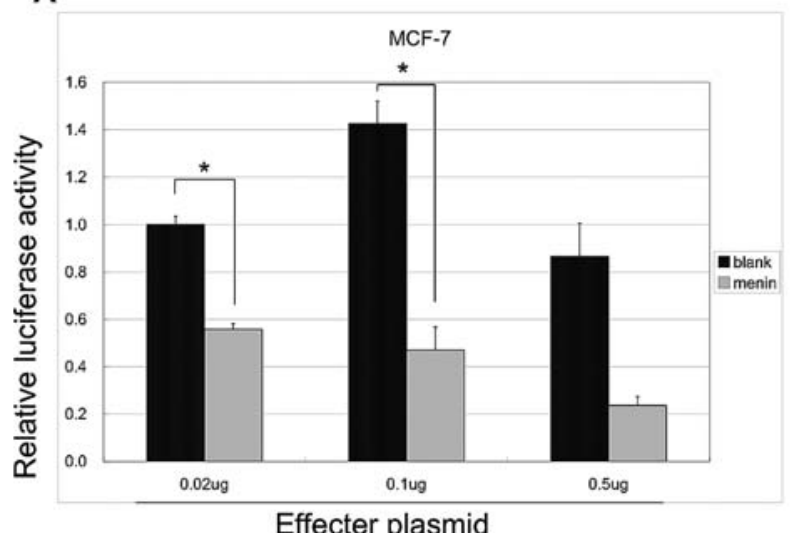

B
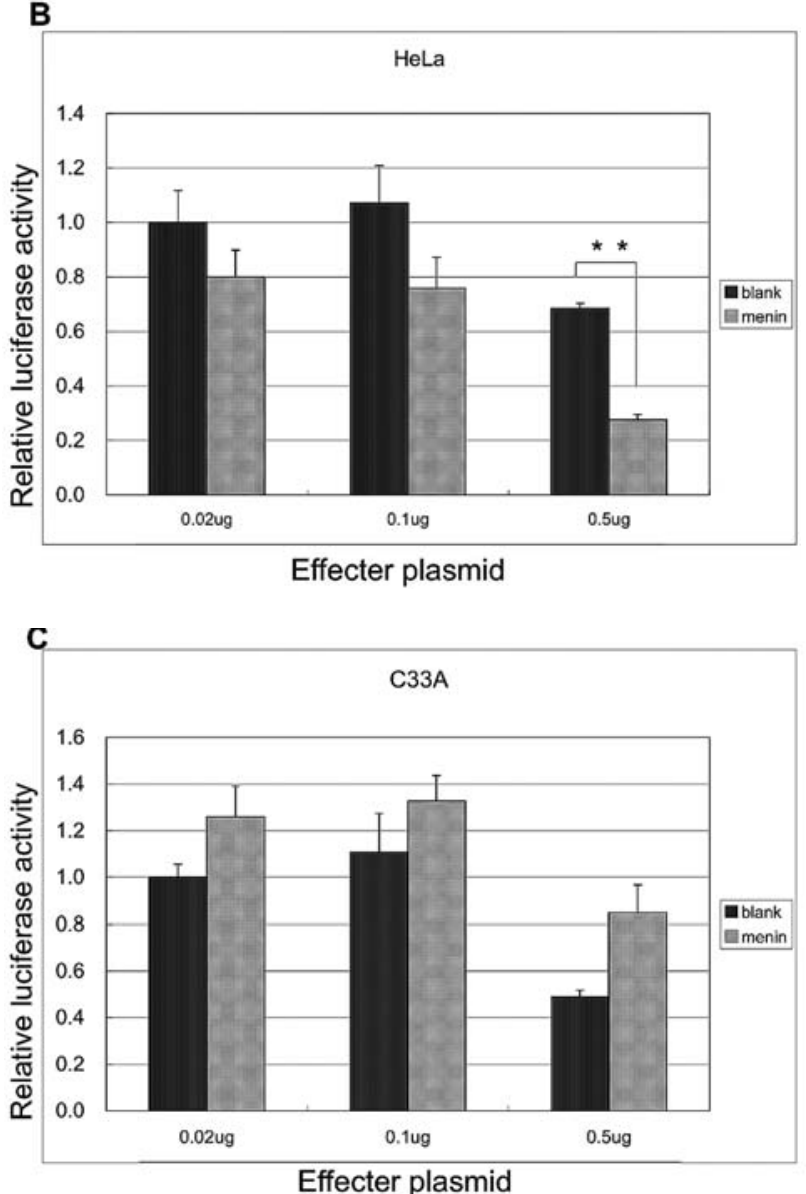

Figure 1. Effect of menin on the transcriptional activity of the hTERT promoter. MCF-7 (A), C33A (B) and HeLa (C) were transfected with menin expression vector and reporter plasmids containing $3.3 \mathrm{~kb}$ of the hTERT promoter. Forty-eight hours after the transfection, cell lysates were extracted and the luciferase assays were performed. Relative luciferase activities are shown. Each point represents the mean \pm SD of triplicate determinations. Bars, \pm SD. ${ }^{*} \mathrm{p}<0.05,{ }^{* *} \mathrm{p}<0.01$.

Austin, TX, USA; Catalog \#16708) or scrambled siRNA (Ambion, siRNA control) for $3 \mathrm{~h}$. Cells were then incubated for $48 \mathrm{~h}$, followed by RNA extraction and RT-PCR assays.

\section{Results}

Effects of menin on the hTERT promoter. To evaluate the effects of menin on hTERT transcription in cancer cells, we first performed the luciferase reporter assay, in which menin expression vectors were transfected into several cancer cell lines together with $h T E R T$-promoter reporter plasmids that contained $3.3 \mathrm{~kb}$ upstream sequences of the hTERT gene (5). There was a diversity of the resulting cell types, with an overexpression of the MEN1-inhibited promoter activity in the MCF-7 cells along with a modest overexpression in the HeLa cells, while there was no significant inhibitory effect was observed for the C33A cells (Fig. 1). To identify the promoter elements responsible for this repression, luciferase assays were further performed with HeLa cells. We prepared mutant reporter plasmids with $2.0 \mathrm{~kb}$ of the $h T E R T$ promoter that contained mutations in several of the binding sites for the transcription factors. Menin is known to interact with the Jun family and indirectly represses the promoter of various genes via these proteinprotein interactions $(9,10)$. Therefore, we first tested the effects of menin on the promoters that contained the AP1 site mutations. As shown in Fig. 2, overexpression of MEN1 sustained the inhibitory effect on these mutant promoters, indicating that the AP1 sites are not involved in the meninmediated repression. The critical cis-elements for the transcription of hTERT are the Sp1 and Myc sites, for which mutations at these sites dramatically reduce the basal transcriptional activity (14). Therefore, we next tested the effects of menin on promoters having mutations within these sites. However, with the use of these mutant reporter plasmids, there was no significant change in the repression noted with the MEN1 overexpression (Fig. 2). We then sought to map the menin-responsible elements on the promoter by using the 5 '-deleted promoters. Deletion of the 5 '-sequences of the $2.0 \mathrm{~kb}$ promoter did not affect the degree of inhibition caused by the MEN1 overexpression (Fig. 3), even when the shortest of the fragments spanning -32 to +77 of the $h T E R T$ promoter responded to the MEN1 overexpression. These findings suggest that menin exerts an inhibitory effect on the hTERT promoter in a sequenceindependent manner.

Menin non-specifically binds to the hTERT promoter. To further confirm the non-specific interaction, we examined the in vitro binding of menin to the hTERT promoter using an electrophoresis mobility shift assay. Recombinant menin protein was incubated with the $181 \mathrm{bp}$ core promoter of hTERT in the presence or absence of poly dI-dC. In the absence of poly $\mathrm{dI}-\mathrm{dC}$, there was a significant binding complex of menin with the hTERT promoter, with the bands broadly localized on gels (Fig. 4). Such complexes were completely diminished by the addition of poly dI-dC. Both longer and shorter promoter fragments were tested as probes, but the results were similar, with the generation of broad bands that completely disappeared upon the addition of poly dI-dC (data not shown). These findings suggest that menin non-specifically binds to the hTERT promoter, as has been reported for other gene promoters (16).

Effects of menin on the levels of hTERT mRNA, hTERT protein and telomerase activity in cancer and normal cells. The effects of menin on hTERT mRNA expression were then examined by overexpressing menin in cancer cells (Fig. 5). 
A

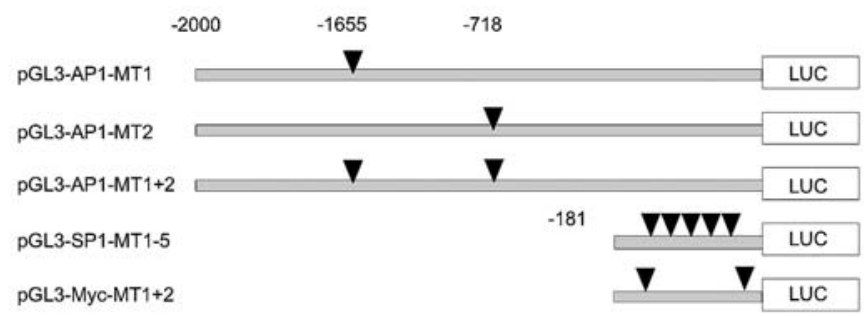

B
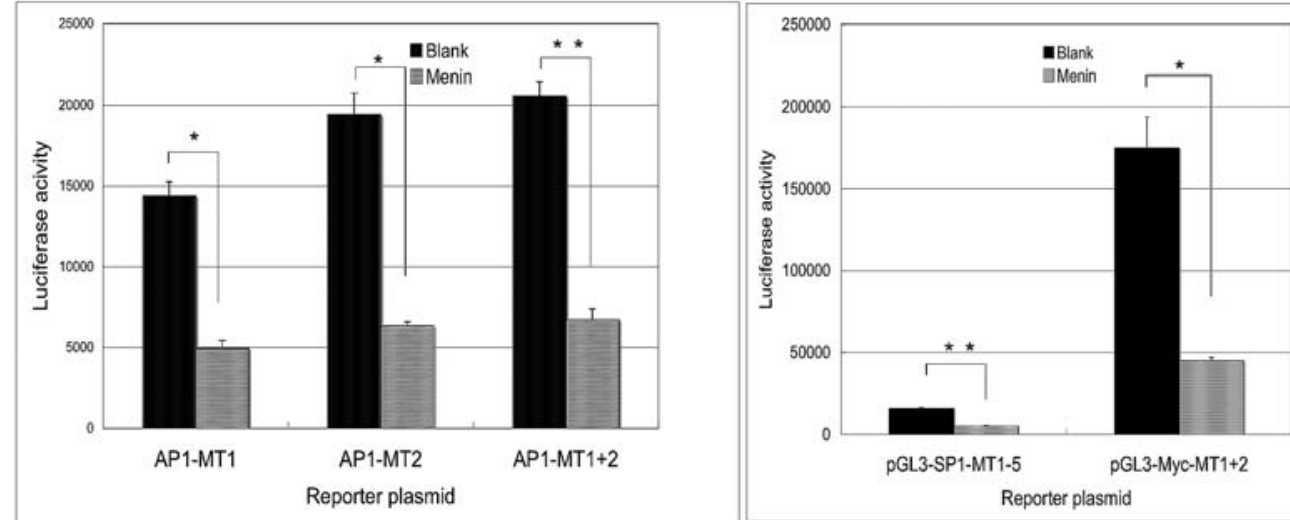

Figure 2. Responsiveness of menin to the mutant promoter of hTERT. HeLa cells were transfected with menin expression vector and hTERT promoter reporter plasmids containing substitution mutations at the binding sites for AP1 (pGL3-AP1-MT1, -MT2, -MT-1+2) (15), SP1 (pGL3-AP1-MT1-5) (14) or Myc (pGL3-AP1-MT1+2) (14). Forty-eight hours after the transfection, cell lysates were extracted and the luciferase assays were performed. (A) Schematic diagram showing the reporter plasmids that were used. Arrowheads represent the factor binding site mutations. (B) Relative luciferase activities are shown. Each point represents the mean $\pm \mathrm{SD}$ of triplicate determinations. Bars, $\pm \mathrm{SD}$. ${ }^{*} \mathrm{p}<0.05,{ }^{* * *} \mathrm{p}<0.01$

A

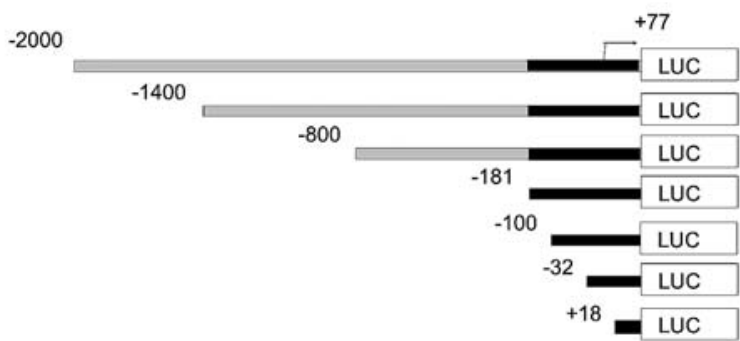

PGL3-2000

PGL3-1400

pGL3-800

PGL3-181

PGL3-100

pGL3-32

PGL3+18

B
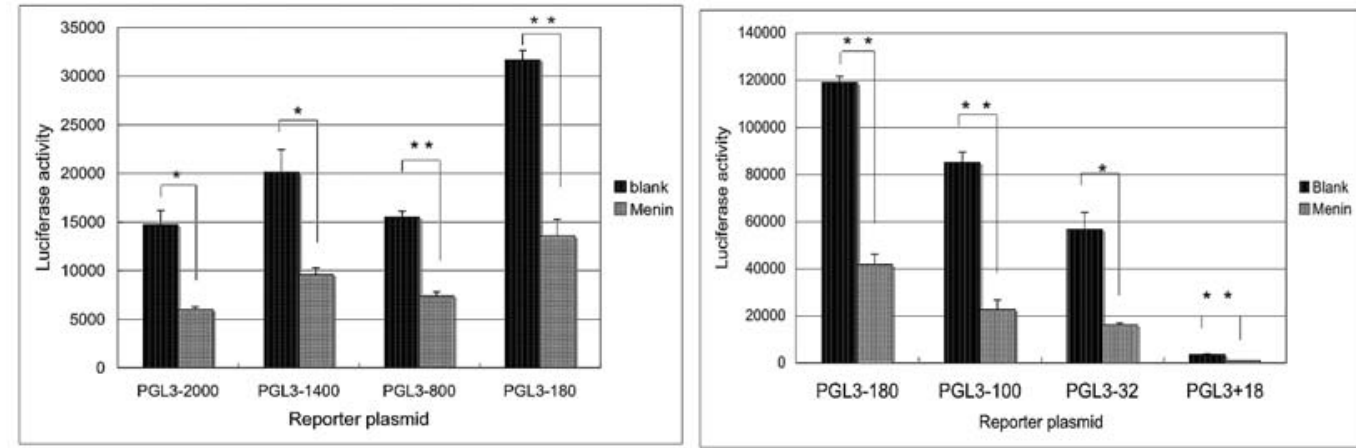

Figure 3. Identification of menin-responsive region in the $h T E R T$ promoter. HeLa cells were transfected with menin expression vectors and $h T E R T$ promoter reporter plasmids containing various lengths of the 5'-upstream sequences of the transcription start site (5). Forty-eight hours after the transfection, cell lysates were extracted and the luciferase assays were performed. (A) Schematic diagram showing the reporter plasmids that were used. Black boxes represent the core promoter responsible for the basal transcription of hTERT (5). Arrowheads represent the transcription start site. (B) Relative luciferase activities are shown. Each point represents the mean $\pm \mathrm{SD}$ of triplicate determinations. Bars, $\pm \mathrm{SD} .{ }^{*} \mathrm{p}<0.05,{ }^{* *} \mathrm{p}<0.01$.

We first confirmed the levels of menin mRNA expression through the use of quantitative RT-PCR assays when the menin expression vector was transiently overexpressed in HeLa, C33A and MCF-7 cells. As shown in Fig. 5A, we 


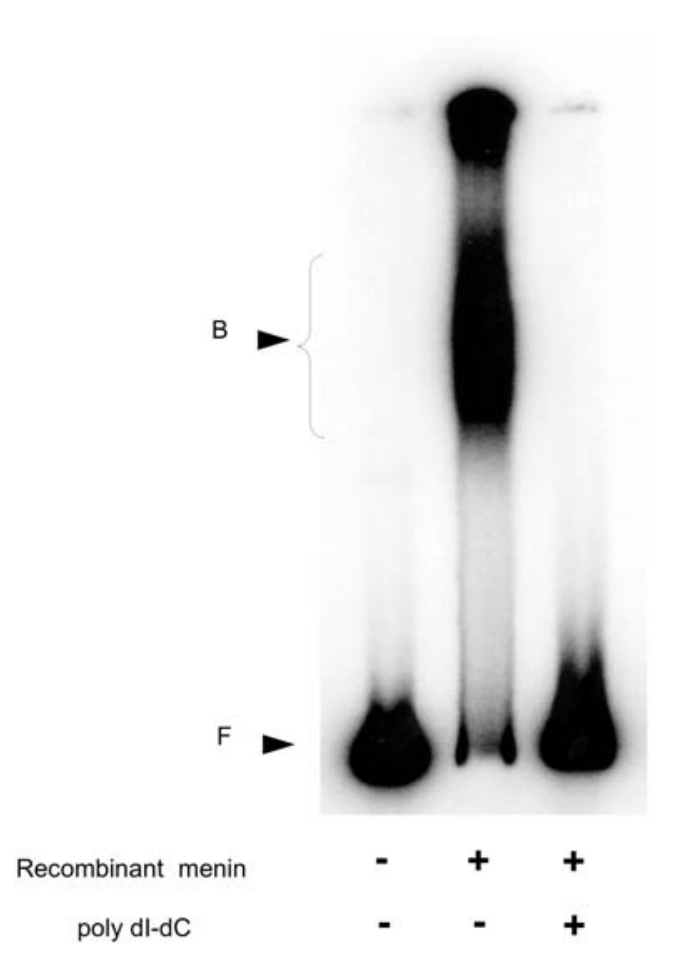

Figure 4. Binding of menin to the hTERT promoter. Recombinant menin proteins were incubated with a $\left[{ }^{32} \mathrm{P}\right]$-end-labeled probe containing $181 \mathrm{bp}$ of hTERT core promoter in the absence or presence of poly dI-dC. Electrophoresis on $5 \%$ polyacrylamide gel was then performed. Retarded bands (shown as B) represent binding complexes. These complexes were completely diminished by the addition of poly-dI-dC. F, unbound free probe.

found that menin was successfully overexpressed. Under the same conditions we then examined the hTERT mRNA expression through the use of quantitative RT-PCR. In HeLa cells, hTERT mRNA expression decreased with menin overexpression up to $40 \%$ of the control (Fig. 5B). However, in C33A and MCF-7 cells, there were no significant changes in hTERT mRNA expression observed. Telomerase activity was next examined by the TRAP assay (Fig. 5C). No significant changes in telomerase activity were detected for any of the cell types examined. This was especially so for the HeLa cells, for which despite the substantial decrease in hTERT mRNA levels, the telomerase activity did not change. This finding suggests that the changes in the hTERT mRNA levels caused by menin do not significantly affect the levels of telomerase activity.

Since overexpression of menin might be far from actual physiological conditions, allowing 10-1000-fold induction of the proteins, we attempted the knockdown of MEN1 in order to investigate the effects on the hTERT mRNA expression in cancer and normal cells (Fig. 6). The siRNA against MEN1 was prepared and introduced into HeLa, NHF and BJ cells, followed by menin mRNA expression examination, which was performed through the use of real-time RT-PCR. Using controls for comparison, sufficient knockdown of MEN1 was first confirmed in these cells (Fig. 6A). In the HeLa cells, although there was slight elevation of hTERT mRNA expression, the change was not statistically significant (Fig. 6B). In NHF and BJ cells, no detectable hTERT mRNA expression was observed in the control samples, as these were normal cells. Even after
A

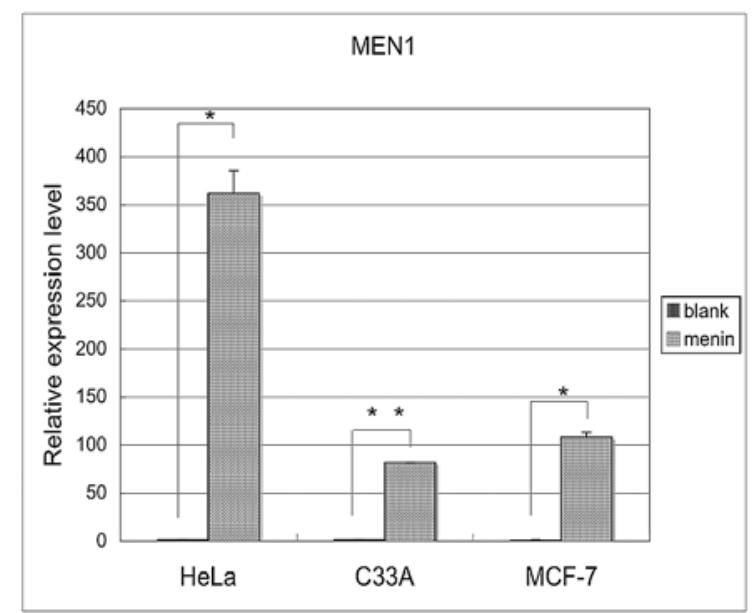

B

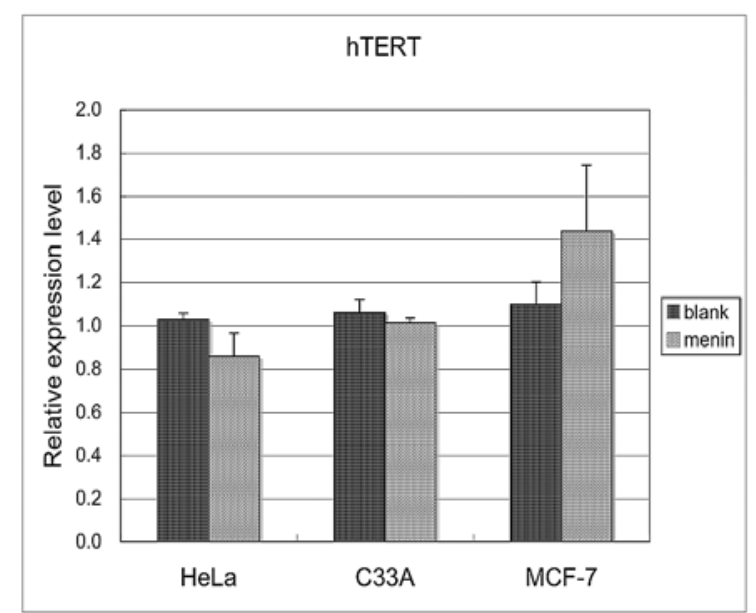

C
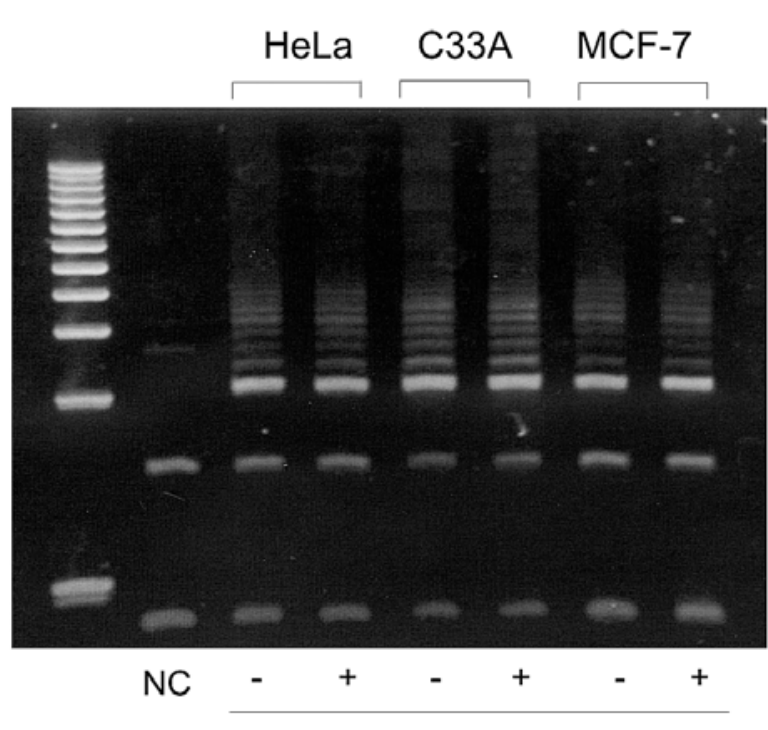

Menin overexpression

Figure 5. Effect of menin on hTERT mRNA expression and telomerase activity. Menin expression vectors were transfected to HeLa, C33A and MCF-7 cells, and mRNA expressions of menin (A) and hTERT (B) were examined by real-time RT-PCR. Relative levels of mRNA expression are shown. Each column represents the mean \pm SD of triplicate determinations. Bars, \pm SD. (C) Telomerase activity was examined by the TRAP assay. $\mathrm{NC}$, negative control with lysis buffer alone. ${ }^{*} \mathrm{p}<0.05,{ }^{* *} \mathrm{p}<0.01$.

MEN1 siRNA was introduced into these cells, there was no induction of hTERT mRNA expression observed (Fig. 6C). These findings suggest that down-regulation of MEN1 does 
A

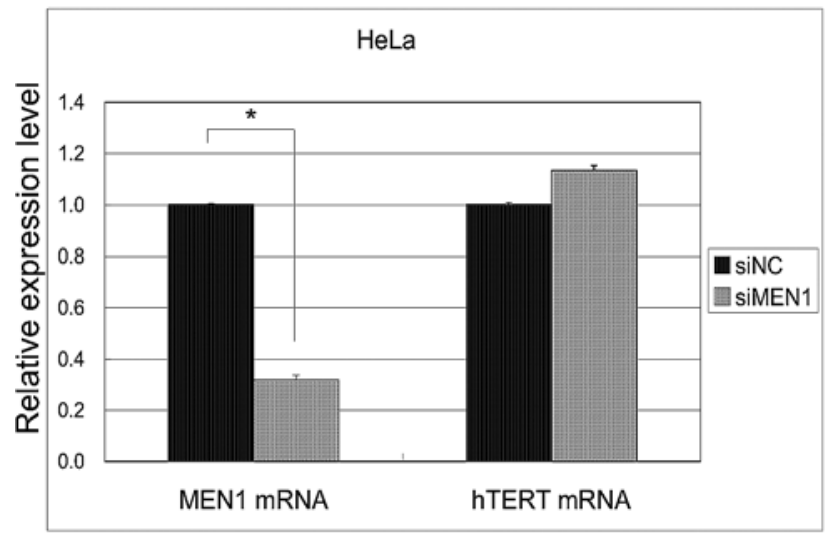

B
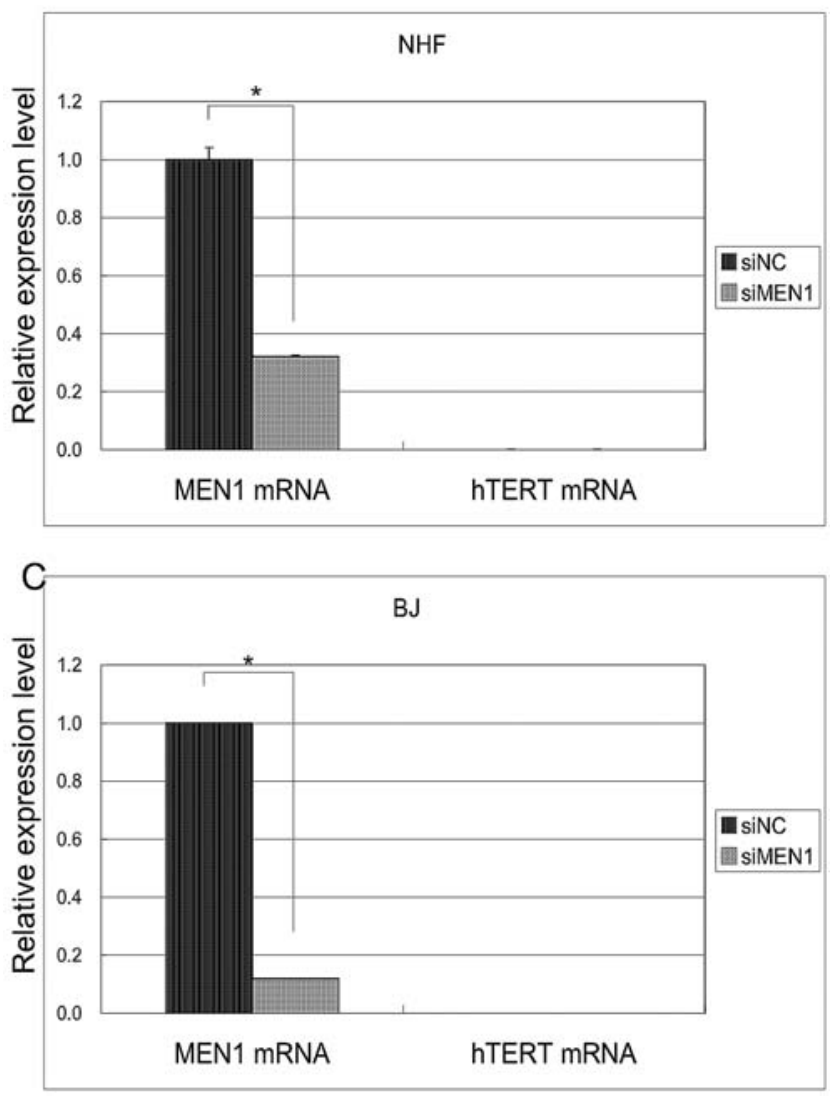

Figure 6. Effect of MEN1-knockdown on hTERT mRNA expression. siRNAs against MEN1 (siMEN1) as well as the scrambled siRNAs as negative controls (siNC) were transfected to HeLa, NHF and BJ cells, and menin and hTERT mRNA expressions were examined by the real-time RT-PCR. Relative levels of mRNA expression are shown. Each column represents the mean $\pm \mathrm{SD}$ of triplicate determinations. Bars, $\pm \mathrm{SD}$. ${ }^{*} \mathrm{p}<0.05$.

not lead to the up-regulation or induction of hTERT mRNA expression in either cancer or normal cells.

Relationship between menin and hTERT expression in various cancer and normal cells and tissues. We finally examined the expression of menin and hTERT in human cancer and normal cells and tissues. Fig. 7A shows the representative results of RT-PCR in various cancer cell lines and normal cells. Expression of menin mRNA was examined
A Cancer cell lines Normal cell lines

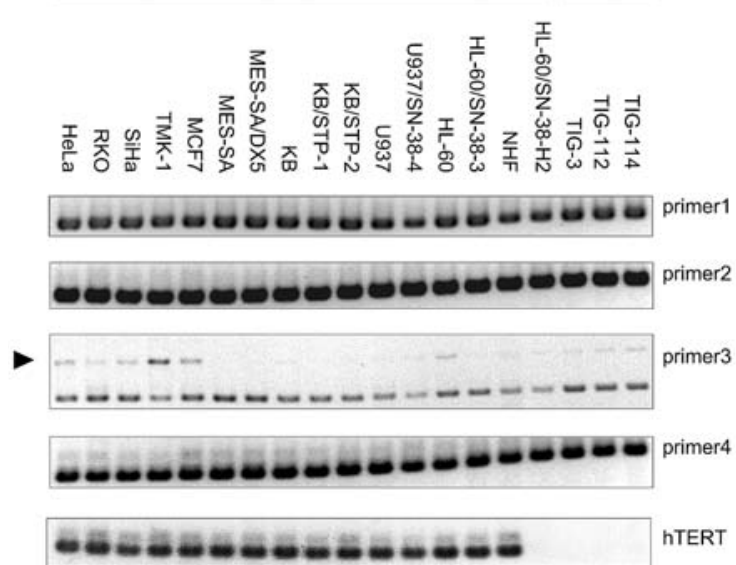

MEN1

B

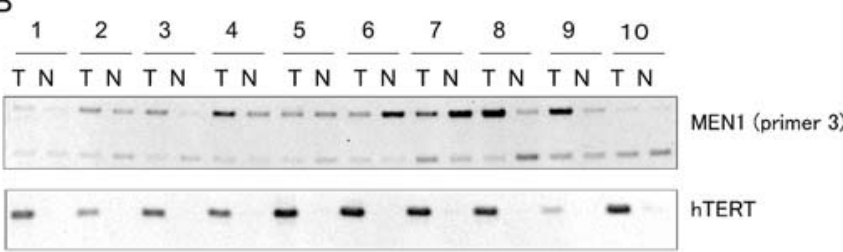

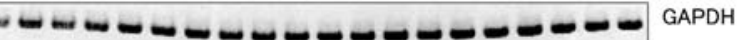

Figure 7. Relationship between menin and hTERT mRNA expression in cell lines and clinical tissue samples. (A) Menin mRNA expressions were examined in various cell lines with different primer settings by RT-PCR, and compared with hTERT mRNA expressions. Note that novel splicing variants of menin (shown as arrowheads) were detected using primer 3. (B) Menin mRNA expressions were examined in liver cancer tissues as well as in their normal liver counterpart by RT-PCR. Results were compared with hTERT mRNA expressions. T, tumor sample; $\mathrm{N}$, normal counterpart.

using 4 different sets of primers. All of the cell lines tested were found to express menin mRNA. We identified bands with unexpected size using a specific primer set (primer 3). We sequenced these diverse bands and found that they were spliced variants with a novel $293 \mathrm{bp}$ insertion. We compared the expression of these transcripts with hTERT mRNA expression for each of the cell lines. No significant correlation was observed between them, as all of the cancer cell lines expressed considerable levels of both $h T E R T$ and MEN1 transcripts. In normal cells (NHF, TIG3, TIG -112, TIG-114), the expressions of these transcripts were noted to be at similar levels as the cancer cell lines, although these cells constitutively lacked the hTERT mRNA that we had expected would be found.

We also examined the expression of menin and hTERT in cancer and normal tissue samples (Fig. 7B). Tumor tissues and the normal counterparts of biopsied or surgical specimens from a total of 10 patients with liver cancers were subjected to RT-PCR assays. Liver cancer tissues exhibited significant levels of hTERT mRNA expression, while the normal counterparts did not. The expression of menin mRNA varied among samples and also between the tumor and normal counterparts from the patients. However, there was no correlation observed between menin and hTERT mRNA expression in these clinical tissue samples. 


\section{Discussion}

Menin is the product of the MEN1 gene, which is classified as the gatekeeper tumor suppressor gene, and which directly controls cell growth and death (17). The MEN1 gene can be inactivated via a biallelic loss-of-function mechanism, in which one hit can be in the form of a small germline or somatic mutations, leading to the development of both familiar and sporadic endocrine tumors. The exact function of menin is unknown, but overexpression of menin inhibits cell proliferation and tumorigenicity, and therefore it is thought to be a tumor suppressor (18). The molecular mechanisms through which menin exerts an inhibitory effect on cell growth are complex, with several menin-interacting proteins reported to play essential roles in its function (16). JunD is a representative factor that interacts with menin $(9,10)$. Recent studies have demonstrated that JunD might normally exist as a complex with menin, rather than in the free form (10). Its association with menin appears to reverse the effect of JunD on cell growth, while free JunD acts a growth promoter when it is unable to bind menin. When binding to menin does occur, this leads to the formation of a growth suppressor complex (19). Interestingly, menin has an mSin3-interacting domain (SID) alpha-helix within its central region, which has been found to recruit histone deacetylase complexes (HDACs) via association with $\mathrm{mSin} 3 \mathrm{~A}$, a general transcriptional corepressor $(12,13)$. This suggests that by recruiting a Sin3A-HDAC complex, menin might be able to serve as a tumor suppressor.

The present study demonstrated that overexpression of menin inhibited the transcriptional activity of the hTERT promoter as well as the hTERT mRNA expression in some but not all cell types, suggesting that menin is a potential transcriptional repressor of hTERT. Based on known findings that JunD is a mediator of menin function, we examined the roles of AP1 in menin-mediated regulation of the $h T E R T$ promoter. However, mutations in the AP1 sites on the hTERT promoter did not abolish the effect of menin. Thus, it is unlikely that menin's inhibitory effect occurs via any interaction with JunD. It has been reported that epigenetic mechanisms via histone deacetylation of the core promoter of hTERT might be involved in promoter silencing, for which $\mathrm{Sp} 1$ plays a central role by recruiting HDAC to the promoter (20). To examine the involvement of such epigenetic regulation in menin-mediated transcriptional repression, we eliminated the Sp1 sites on the hTERT promoter by introducing substitution mutations. However, menin-mediated repression of the $h T E R T$ transcription was not abolished in these mutant reporters. Furthermore, treatment of the cells with an HDAC inhibitor, trichostatin A, did not significantly recover the menin-mediated repression (data not shown). Thus, it is unlikely that such epigenetic mechanisms are involved in the menin-mediated repression of hTERT.

While our data did demonstrate that menin binds to the hTERT promoter, this binding was not sequence-specific. Furthermore, menin-mediated repression of the hTERT transcription was observed throughout the promoter regions tested as all of the 5'-deleted promoters responded similarly to the overexpression of MEN1 in reporter assays. Thus, we concluded that menin exerts its inhibitory effect via a sequence-independent binding to the promoter. Our results are consistent with a recent report that found that menin has the ability to bind double-stranded DNA in a sequenceindependent manner via its C-terminal region, for which there are two nuclear localization signals (NLS) that are essential for the direct DNA binding (16). Multiple positively charged lysine or arginine residues in the NLSs are thought to play a role in the DNA binding by simply binding to the negative charge (16). The precise molecular mechanisms through which non-specific binding of menin leads to transcriptional repression of $h T E R T$ remain unclear. One possible explanation is that menin binding may disturb the interaction of the multiple transcriptional activators with the promoter. The present electrophoretic mobility shift showed extremely broad bands of menin-DNA complexes, suggesting that there are numerous menin molecules that bind to and occupy the promoter. Therefore, menin may suppress the promoter activity simply by disturbing the binding or interaction of the various transcription factors to the promoter. Alternatively, it is possible that menin binding may affect chromatin structure, a possibility that we are currently in the process of examining.

In the present study, there were no significant correlations between menin expression and hTERT mRNA expression found between the various cell lines and clinical samples. In normal liver tissues, expression levels of menin varied among samples, with some expressing high levels of menin, while in others, there was no expression exhibited at all. Nevertheless, in all samples there was no hTERT mRNA expression noted by RT-PCR. Our in vitro analyses revealed that siRNA-mediated inhibition of the MEN1 gene did not lead to induction of hTERT mRNA expression in normal cells. This is in contrast to the recent observation by Lin et al (6), who reported that siRNA inhibition of MEN1 dramatically induced telomerase activity in BJ cells, thus conferring susceptibility for the cell transformation of normal cells. At present, we do not know the reason for the discrepancy between our results and their data. However, while menin may have a role in the repression of TERT transcription, there is no convincing evidence that disruption of a single repressor can lead to a dramatic activation of telomerase in telomerase-negative normal cells. At present, our data indicate that there is no involvement of menin in the silencing of $h T E R T$ in normal cells.

What then are the biological roles for menin in hTERT regulation? As shown in our study, there was no correlation between hTERT mRNA expression and menin expression in the various cell lines and tissues. This suggests that menin is not a critical determinant of telomerase activity in normal and cancer cells. Numerous other studies have tried to identify the transcriptional factors critical for hTERT regulation but have failed to find any specific factors that are responsible for determining the telomerase activity in cells. It is now widely accepted that a number of nuclear factors are involved in the regulation of $h T E R T$ transcription and that the levels of hTERT expression are determined by the sum of the effects of the individual factors. Within these complex regulatory mechanisms, while menin appears to have a role, nevertheless, this role is not as a potent inhibitory factor in TERT transcription. While constitutive expression of menin in 
normal and cancer cells may have effects on the modulating promoter activity of $h T E R T$, the present study does not support the hypothesis that menin has a crucial role as a determinant of telomerase activity in either cancer or normal cells. These findings are a reminder that careful biochemical analyses are needed to verify whether so-called hTERT repressors are real functional repressors.

\section{Acknowledgments}

We greatly thank Dr Sunita K. Agarwal, at the National Institute of Diabetes and Digestive and Kidney Diseases and the National Institutes of Health, Bethesda, Maryland, for kindly providing the menin expression vector. This study was supported by a Grant-in-Aid for Scientific Research from the Japan Society for the Promotion of Science (JSPS) and the Megumi Medical Foundation of Kanazawa University.

\section{References}

1. Kim NW, Piatyszek MA, Prowse KR, Harley CB, West MD, Ho PL, Coviello GM, Wright WE, Weinrich SL and Shay JW: Specific association of human telomerase activity with immortal cells and cancer. Science 266: 2011-2015, 1994.

2. Kyo $S$ and Inoue M: Complex regulatory mechanisms of telomerase activity in normal and cancer cells: how can we apply them for cancer therapy? Oncogene 21: 688-697, 2002.

3. Nakamura TM, Morin GB, Chapman KB, Weinrich SL, Andrews WH, Lingner J, Harley CB and Cech TR: Telomerase catalytic subunit homologs from fission yeast and human. Science 277: 955-959, 1997.

4. Meyerson M, Counter CM, Eaton EN, Ellisen LW, Steiner P, Caddle SD, Ziaugra L, Beijersbergen RL, Davidoff MJ, Liu Q, Bacchetti S, Haber DA and Weinberg RA: hEST2, the putative human telomerase catalytic subunit gene, is up-regulated in tumor cells and during immortalization. Cell 90: 785-795, 1997.

5. Takakura M, Kyo S, Kanaya T, Takeda J, Yutsudo M, Hirano H and Inoue $\mathrm{M}$ : Cloning of human telomerase reverse transcriptase gene promoter and identification of proximal core promoter essential for transcriptional activation in immortalized and cancer cells. Cancer Res 59: 551-557, 1999.

6. Lin SY and Elledge SJ: Multiple tumor suppressor pathways negatively regulate telomerase. Cell 113: 881-889, 2003.

7. Guo SS and Sawicki MP: Molecular and genetic mechanisms of tumorigenesis in multiple endocrine neoplasia type-1. Mol Endocrinol 15: 1653-1664, 2001.
8. Balogh K, Rácz K, Patócs A and Hunyady L: Menin and its interacting proteins: elucidation of menin function. Trends Endocrinol Metab 17: 357-364, 2006.

9. Agarwal SK, Guru SC, Heppner C, Erdos MR, Collins RM, Park SY, Saggar S, Chandrasekharappa SC, Collins FS, Spiegel AM, Marx SJ and Burns AL: Menin interacts with the AP1 transcription factor JunD and represses JunD-activated transcription. Cell 96: 143-152, 1999.

10. Yazgan $\mathrm{O}$ and Pfarr CM: Differential binding of the menin tumor suppressor protein to JunD isoforms. Cancer Res 61: 916-920, 2001.

11. Heppner C, Bilimoria KY, Agarwal SK, Kester M, Whitty LJ, Guru SC, Chandrasekharappa SC, Collins FS, Spiegel AM, Marx SJ and Burns AL: The tumor suppressor protein menin interacts with NF-kappaB proteins and inhibits NF-kappaBmediated transactivation. Oncogene 20: 4917-4925, 2001.

12. Kim H, Lee JE, Cho EJ, Liu JO and Youn HD: Menin, a tumor suppressor, represses JunD-mediated transcriptional activity by association with an $\mathrm{mSin} 3 \mathrm{~A}$-histone deacetylase complex. Cancer Res 63: 6135-6139, 2003.

13. Gobl AE, Berg M, Lopez-Egido JR, Oberg K, Skogseid B and Westin G: Menin represses JunD-activated transcription by a histone deacetylase-dependent mechanism. Biochem Biophys Acta 1447: 51-56, 1999.

14. Kyo S, Takakura M, Kanaya T, Taira T, Kanaya T, Itoh H, Yutsudo M, Ariga $\mathrm{H}$ and Inoue M: Sp1 cooperates with c-Myc to activate transcription of human telomerase reverse transcriptase (hTERT) gene. Nucleic Acids Res 28: 669-677, 2000 .

15. Takakura M, Kyo S, Inoue M, Wright WE and Shay JW: The function of AP1 on transcription of telomerase reverse transcriptase gene (TERT) in human and mouse cell. Mol Cell Biol 18: 8037-8043, 2005.

16. La P, Silva AC, Hou Z, Wang H, Schnepp RW, Yan N, Shi Y and Hua X: Direct binding of DNA by tumor suppressor menin. J Biol Chem 279: 49045-49054, 2004.

17. Marx SJ and Simonds WF: Hereditary hormone excess: genes, molecular pathways and syndromes. Endocr Rev 26: 615-661, 2005.

18. Collins FS, Spiegel AM and Marx SJ: Stable overexpression of MEN1 suppresses tumorigenicity of RAS. Oncogene 18: 5936-5942, 1999.

19. Agarwal SK, Novotny EA, Crabtree JS, Weitzman JB, Yaniv M, Burns AL, Chandrasekharappa SC, Collins FS, Spiegel AM and Marx SJ: Transcription factor JunD, deprived of menin, switches from growth suppressor to growth promoter. Proc Natl Acad Sci USA 100: 10770-10775, 2003.

20. Takakura M, Kyo S, Sowa Y, Wang Z, Yatabe N, Maida Y, Tanaka $\mathrm{M}$ and Inoue $\mathrm{M}$ : Telomerase activation by histone deacetylase inhibitor in normal cells: induction of hTERT expression through Sp1 binding sites. Nucleic Acids Res 29: 3006-3011, 2001. 